Full length article

\title{
Functional inactivation of the orbitofrontal cortex disrupts context-induced reinstatement of alcohol seeking in rats
}

\author{
Paula Cristina Bianchi ${ }^{\mathrm{a}, \mathrm{b}}$, Paulo Eduardo Carneiro de Oliveira ${ }^{\mathrm{a}}$, Paola Palombo ${ }^{\mathrm{a}, \mathrm{b}}$, \\ Rodrigo Molini Leão ${ }^{\mathrm{c}}$, Hugo Cogo-Moreira ${ }^{\mathrm{d}}$, Cleopatra da Silva Planeta ${ }^{\mathrm{a}, \mathrm{b}}$, Fábio Cardoso Cruz ${ }^{\mathrm{e}, *}$

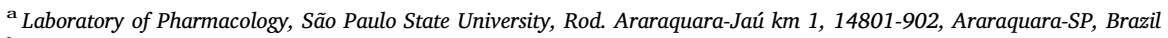 \\ b Joint Graduate Program in Physiological Sciences, Federal University of São Carlos and São Paulo State University Araraquara, Rod. Washington Luís km 235, 13565- \\ 905, São Carlos-SP, Brazil \\ ${ }^{\mathrm{c}}$ Bioregulation Department Federal University of Bahia, UFBA, Av. Reitor Miguel Calmon $s / n$ Vale do Canela Salvador/BA, Brazil \\ d Department of Psychiatry, São Paulo Federal University, R. Dr. Ovidio Pires de Campos, 78505403-903, SP, Brazil \\ e Department of Pharmacology, São Paulo Federal University, Leal Prado Building, Botucatu 862 Street, 04024-002, Vila Clementino, São Paulo-SP, Brazil
}

\section{A R T I C L E I N F O}

\section{Keywords:}

Alcohol self-administration

Orbitofrontal cortex

Male and female rats

Functional inactivation

\begin{abstract}
A B S T R A C T
Background: The high rate of relapse to drug use remains a central challenge to treating drug addiction. In human and rat models of addiction, environmental stimuli in contexts associated with previous drug use can provoke a relapse of drug seeking. Pre-clinical studies have used the ABA renewal procedure to study contextinduced reinstatement of drug seeking. In the current study, we studied the role of the orbitofrontal cortex (OFC) in context-induced reinstatement to alcohol.

Methods: We trained male and female rats to self-administer alcohol in context A, extinguished drug-reinforced responding in a distinct context $\mathrm{B}$, and assessed context-induced reinstatement in context A or B (control group). Next, we determined the effect of context-induced renewal of alcohol-seeking behavior on the expression of Fos (a neuronal activity marker) in the OFC. Finally, we determined the effect of reversible inactivation by GABAa and GABAb receptor agonists (i.e., muscimol and baclofen, respectively) in the OFC.

Results and conclusions: There were no differences between male and female rats in context-induced reinstatement of alcohol-seeking behavior. Re-exposure to Context A, but not Context B, reinstated alcohol-seeking behavior and increased expression of the neural activity marker Fos in the OFC. Reversible inactivation of the OFC with muscimol and baclofen attenuated context-induced reinstatement. Our data indicated that the OFC mediates context-induced reinstatement of alcohol-seeking behavior.
\end{abstract}

\section{Introduction}

Alcohol addiction is characterized by high rates of relapse, which is a major problem in treating alcoholism (Fox et al., 2008; Sinha, 2009). Clinical and pre-clinical studies have demonstrated that the environmental context in which drugs are used can influence subsequent pharmacological effects of drugs as well as increase susceptibility to relapse (Janak and Chaudhri, 2010; O'Brien et al., 1990; Wikler, 1973). For instance, exposure to environments previously associated with drinking can contribute to precipitating drug-taking behavior in abstinent patients (Ludwig et al., 1974; Staiger and White, 1991).

Some animal models were developed to study the effect of environmental contexts on drug-seeking relapse. In rats, the ABA renewal procedure has been used to study context-induced relapse to alcoholseeking behavior (Bouton and King, 1983; Crombag and Shaham,
2002). In this procedure, rats are trained to self-administer a drug paired with discrete cues in one context (A). The lever response is then removed in a different (non-drug) context (B) in the presence of discrete cues. In the end, rats are re-exposed to the drug-associated context (A). Several studies demonstrated that exposure to the alcohol self-administration context after the removal of the alcohol lever in a different context reinstated alcohol seeking in rats (Burattini et al., 2006; Hamlin et al., 2007; Janak and Chaudhri, 2010; Marchant et al., 2013).

Although the neural pathway mediating cue-induced alcohol craving (humans) or seeking (nonhumans) is complex, evidence from human brain imaging shows that important behaviors related to addiction, such as compulsive drug use and drug relapse, are mediated at least in part by drug-induced plasticity in the orbitofrontal cortex (OFC) (London et al., 2000). In rats, cue-induced cocaine and heroin seeking has been associated with increased expression of neuronal activation

\footnotetext{
* Corresponding author at: Pharmacology Department, São Paulo Federal University, Botucatu Street, 862 - Ed. Leal Prado 1st floor, SP, Brazil.

E-mail address: f.cruz@unifesp.br (F.C. Cruz).
} 
markers in the OFC (Fanous et al., 2012; Morgan and Curran, 1991; Thomas et al., 2003). Further, the reversible inactivation of this brain region decreases discrete cue-induced reinstatement of cocaine and heroin seeking in rats (Fanous et al., 2012; Fuchs et al., 2004; Lasseter et al., 2009).

The OFC connects with limbic areas, such as the basolateral amygdala (BLA) and nucleus accumbens, to enable encoding of memories (Schoenbaum and Shaham, 2008). Clinical studies with cocaine users demonstrated that exposure to cocaine-paired stimuli enhanced neural activity in the BLA and OFC, which was positively correlated with self-reports of cocaine craving (Childress et al., 1999; Grant et al., 1996; Kilts et al., 2001; London et al., 1999). In addition, Lasseter et al. (2011) demonstrated that administration of muscimol + baclofen to the BLA and OFC profoundly attenuated the reinstatement of drug context-induced cocaine seeking behavior. These findings indicated that the BLA and OFC are integral parts of the mesocorticolimbic neural circuitry known to direct cue and context-induced cocaine-seeking behavior in animal models of drug relapse. Despite the evidence demonstrating the role of OFC in conditioned behaviors, the relevance of this brain region in context-induced alcohol seeking has never been investigated.

To address this, we used Fos immunohistochemistry to characterize the involvement of the OFC in context-induced reinstatement of alcohol-seeking. Then, we combined reversible inactivation of the OFC, using muscimol and baclofen (i.e., GABAa and GABAb agonists, respectively), to assess whether the OFC mediates context-induced reinstatement of alcohol-seeking behavior. In addition, we assessed behavioral differences in context-induced reinstatement of alcohol seeking between female and male rats.

\section{Method}

\subsection{Animals}

Male $(\mathrm{n}=38)$ and Female $(\mathrm{n}=39)$ Long-Evans rats, weighing 250-350 g (obtained from the animal breeding facility of the São Paulo State University), were used for the current study. Groups of four animals were housed in plastic cages, which were $32 \times 40 \times 16 \mathrm{~cm}$, in a room maintained at $23 \pm 2{ }^{\circ} \mathrm{C}$. Rats were continuously maintained on a reversed light cycle (i.e., 12:12 h, lights off at 08:00 a.m.), with a controlled temperature $\left(23^{\circ} \mathrm{C}\right)$ and unrestricted access to food and water. All experiments were performed during the dark phase. The experimental protocol was approved by the Ethical Committee for Use of Animals of the Physical Institute of São Carlos, São Paulo University (Protocol \# 01/2015) and were conducted according to ethics principles of the Conselho Nacional de Controle de Experimentação Animal (CONCEA).

We excluded 18 of the 77 rats ( 10 male and 8 female rats) from all the experiments for the following reasons: 5 due to inadequate training ( $<15$ reinforcements/day) or failure to meet an extinction criterion of a mean of $<25$ responses over 5 days, 3 due to surgical procedure complications, and 10 due to misplaced cannula.

\subsection{Apparatus}

Rats were trained and tested in standard Med Associates (St. Albans, VT) self-administration chambers. Each chamber was equipped with two levers that were located $9 \mathrm{~cm}$ above the grid floor. Presses on the active retractable lever activated the infusion pump, while presses on the inactive non-retractable lever had no programmed consequences. Context A (the alcohol self-administration (training)) and B (extinction) were manipulated and counterbalanced. They differed from each other in terms of grid width (narrow/wide), illumination level (white/red house light), background noise (fan on/off), and background cues (stickers present/absent, cabinet doors close/open), as described by Marchant et al. (2013).

\subsection{Substances}

Saccharin (Sigma-Aldrich, St Louis, MO, USA) was diluted in tap water at a concentration of $0.2 \%$ and $0.05 \%(\mathrm{w} / \mathrm{v})$. Ethanol (EtOH; Sigma-Aldrich, $96 \% \mathrm{v} / \mathrm{v}$, St Louis, MO, USA) was diluted in saccharin solution or tap water to a final concentration of $10 \%$ or $20 \%(\mathrm{w} / \mathrm{v})$. Flunixin Meglumine (Schering-Plough) was dissolved in saline solution $(0.9 \% \mathrm{NaCl})$ in a concentration of $0.5 \mathrm{mg} \mathrm{ml}^{-1}$. Muscimol and baclofen (concentration, $0.06 \mathrm{mM}+0.6 \mathrm{mM}$ ) (Tocris) were dissolved in sterile saline. Streptomycin and Penicillin Polyantibiotic (Fort Dodge) were dissolved in sterile saline $(0.9 \% \mathrm{NaCl})$ at a concentration of $560 \mathrm{mg} \mathrm{ml}^{-1}$. Tribromoethanol (Sigma-Aldrich) was dissolved in saline solution $(0.9 \% \mathrm{NaCl})$ at a concentration of $2.5 \mathrm{mg}$ in $100 \mathrm{ml}$.

\subsection{Behavioral procedures}

The experiments consisted of four phases as follows: home-cage alcohol intake (5 days), EtOH operant self-administration training (18 sessions), extinction (10 sessions), and test for context-induced reinstatement of ethanol seeking (1 session). The experimental sequence was home-cage alcohol intake - Context A (training) - Context B (extinction) - Contexts A and B (testing), as shown in Fig. 1.

\subsubsection{Phase 1: home-cage alcohol intake}

We used a two-bottle choice paradigm in which rats had access to one bottle of alcohol $(20 \% \mathrm{w} / \mathrm{v})$ and one bottle of water for 5 consecutive days in their home cages in order to habituate them to the taste of alcohol (adapted from Marchant et al., 2013).

\subsubsection{Phase 2: alcohol self-administration training}

All self-administration training sessions were performed in Context A. Reinforcements were earned using a fixed ratio 1 (FR-1) 20-s timeout reinforcement schedule. Active lever presses resulted in the presentation of a 2-s tone-light cue $(7.5 \mathrm{~W}$ white light), compound tone $(2900 \mathrm{~Hz} ; 20 \mathrm{~dB})$, and infusion pump activation. During the training phase, the activation of the infusion pump resulted in $0.1 \mathrm{ml}$ of solution administered to the oral space. The initiation of each training session was signaled by the illumination of the house-light and insertion of the active lever into the chamber. Inactive lever presses and responses during the timeout interval had no programmed consequences.

Rats were trained to press a lever for $0.1 \mathrm{ml}$ of $0.2 \%$ saccharin for $1 \mathrm{~h}$ each day for 3 days. We then gradually replaced the saccharin reward with alcohol. Rats were trained to press the lever for $0.1 \mathrm{ml}$ of $0.2 \%$ saccharin $+10 \%$ ethanol $(\mathrm{w} / \mathrm{v})$ for $1 \mathrm{~h}$ each day for 2 days, then for $0.1 \mathrm{ml}$ of $0.05 \%$ saccharin $+10 \%$ ethanol $(\mathrm{w} / \mathrm{v})$ for $1 \mathrm{~h}$ each day for 2 days, and then for $0.1 \mathrm{ml}$ of $10 \%$ ethanol $(\mathrm{w} / \mathrm{v}$ ) alone for $1 \mathrm{~h}$ each day for 6 days. Following FR-1 training, rats were trained to press the lever for $10 \%$ ethanol on a variable-interval $30-\mathrm{s}$ (VI-30) schedule of reinforcement for $1 \mathrm{~h}$ each day for 5 days. The ethanol reinforcement, which was available at pseudo-random intervals (i.e., 1-59 s) following the preceding alcohol delivery, was delivered after an active lever press. Each alcohol delivery was also paired with the same compound tone ( $2900 \mathrm{~Hz} ; 20 \mathrm{~dB}$ above background) and light (a $7.5 \mathrm{~W}$ white light) cues for $2.3 \mathrm{~s}$.

\subsubsection{Phase 3: extinction of alcohol self-administration}

During the extinction phase in Context $\mathrm{B}$, responses on the previously active lever, under a VI-30 schedule of reinforcement, led to presentation of the tone-light cue, compound tone, and activation of the infusion pump, but the alcohol was not delivered. The alcohol self-administration was considered extinguished when the rats met extinction criterion of a mean of $<25$ presses on the previously active lever over the last three extinction sessions.

\subsubsection{Phase 4: test for context-induced reinstatement}

We tested the alcohol-seeking behavior (active lever presses under 


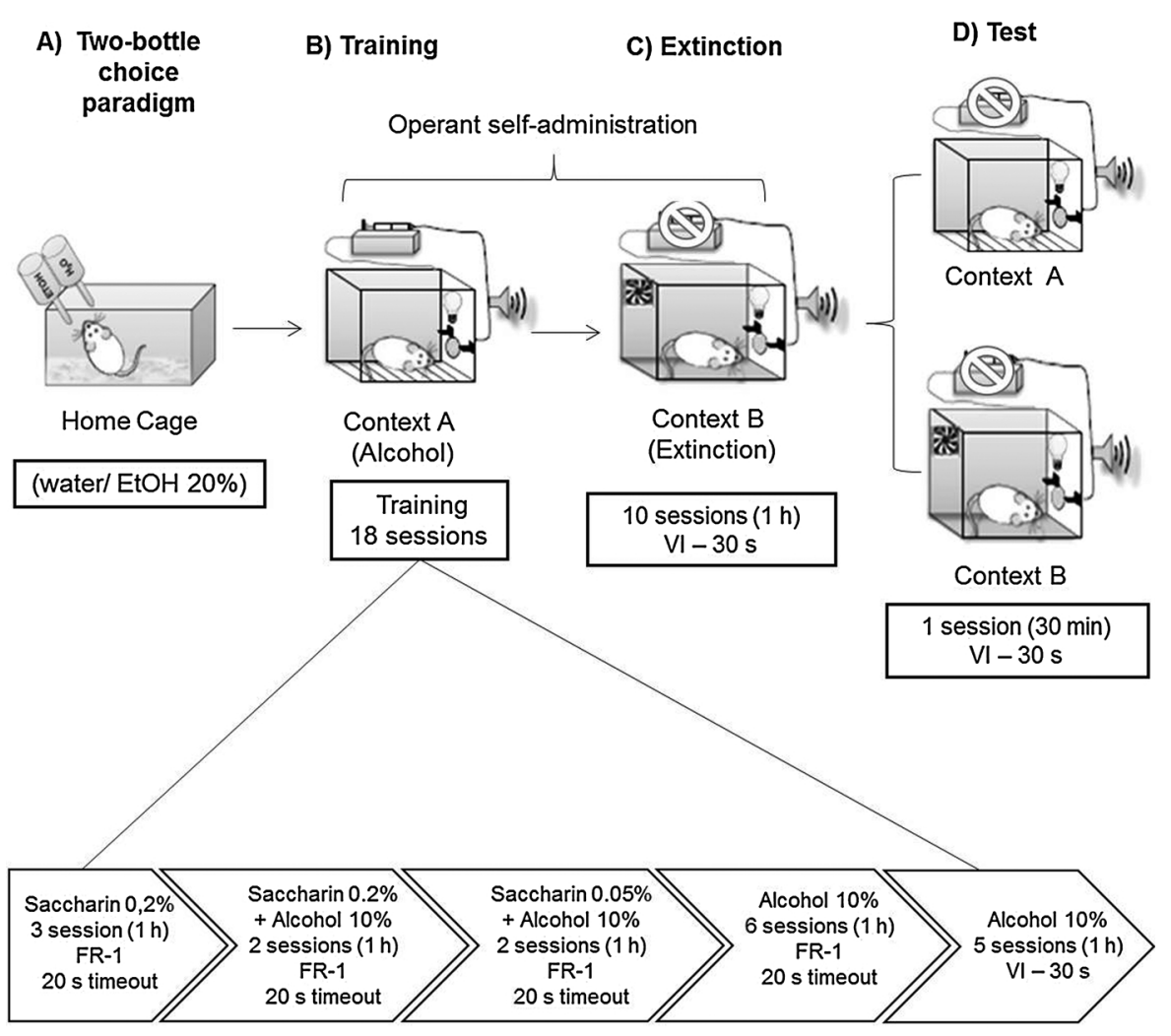

Fig. 1. Schematic representation of the experimental design. Briefly, (A) rats were first given home-cage access to $20 \%$ ethanol. (B) Using a saccharin fading technique, rats are first trained to self-administer $10 \%$ ethanol in context A. (C) Next, lever pressing in the presence of the discrete cue was subsequently extinguished in a different context (B). (D) Subsequently, context-induced reinstatement of drug seeking was assessed by re-exposing rats to the drug-associated or extinction context under extinction conditions.

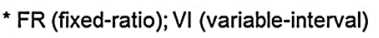

extinction conditions) in the rats during one 30-min session in either Context A or Context B. During the tests, an active lever press, under a VI-30 schedule of reinforcement, resulted in the 2-s tone-light cue and the activation of the infusion pump, but no alcohol was delivered.

\subsection{Blood alcohol levels (BAL)}

Immediately after the end of the last VI 30-s session, blood samples $(100 \mu \mathrm{l})$ were collected from the tip of the tail of some rats. The blood samples were centrifuged, and plasma alcohol levels were measured using an enzymatic system based on measurement of oxygen consumption during the ethanol-acetaldehyde reaction (AM1 Analyzer; Analox Instruments Ltd, London, UK).

\subsection{Intracranial surgery}

We performed all surgeries between the 5th and 6th VI-30 training session. Rats were anesthetized using tribromoethanol $\left(250 \mathrm{mg} \mathrm{kg}^{-1}\right.$, i.p.). Following scalp anesthesia with $2 \%$ lidocaine, the skull was exposed and stainless-steel guide cannulas (26 G, 12-mm-long) were bilaterally implanted into the $\mathrm{OFC}$, at a position that was $1 \mathrm{~mm}$ above the site of injection, using a stereotaxic apparatus (Model 900, Kopf). The coordinates for the OFC (from the Bregma) were as follows (nose bar set at $-3.3 \mathrm{~mm}$ ): anteroposterior (AP), +3.2 ; mediolateral $(\mathrm{ML}),+2.6$ ( $10^{\circ}$ angle); dorsoventral (DV), $-4.0 \mathrm{~mm}$ (Paxinos and Watson, 2005). Cannulae were fixed to the skull with dental cement and five metal screws. After the surgery, the animals received a poly-antibiotic with streptomycin and penicillin $\left(560 \mathrm{mg} \mathrm{ml}^{-1} \mathrm{~kg}^{-1}\right.$, i.m.) to prevent infection and the non-steroidal anti-inflammatory drug flunixin meglumine $\left(0.5 \mathrm{mg} \mathrm{ml}^{-1} \mathrm{~kg}^{-1}\right.$, s.c. $)$ for post-operation analgesia. The rats were allowed to recover for 5 days before being subjected to a VI-30 training session phase again. During the first 3 days of recovery phase, the rats were injected with the anti-inflammatory drug, flunixin meglumine (0.5 $\mathrm{mg} \mathrm{ml}^{-1} \mathrm{~kg}^{-1}$, s.c.).

\subsection{Intracranial injections and histology}

The rats received infusions of saline or a solution containing both muscimol + baclofen (concentration $0.06 \mathrm{mM}+0.6 \mathrm{mM}$, respectively) (Tocris). Intracranial injections were administered using a syringe pump (Harvard Apparatus) and 2- $\mu$ l Hamilton syringes, which were attached via polyethylene 10 tubing to 30-gauge injectors (Plastics One). All microinjections were performed at a volume of $0.5 \mu \mathrm{l}$ per side over $1 \mathrm{~min}$. After allowing an additional $1 \mathrm{~min}$ for diffusion, the microinjectors were removed. The rats were placed into self-administration chambers for testing $15 \mathrm{~min}$ after the microinjection. The doses were based on previous studies (Cruz et al., 2014; Marchant et al., 2014; Willcocks and McNally, 2013). At the end of the test, the rats were given an overdose of tribromoethanol $\left(500 \mathrm{mg} \mathrm{kg}^{-1}\right.$, i.p.). The rat brains were perfused by cardiac perfusion, removed, frozen, and sectioned coronally at a thickness of $40 \mu \mathrm{m}$ using a cryostat. All sections containing the cannula tracts were collected onto glass slides, stained for cresyl violet, and coverslipped with Permount (Sigma). The sections were examined under light microscopy to determine the placements of the cannula tips.

\subsection{Experiment 1: orbitofrontal cortex neuronal activation after context- induced the reinstatement of ethanol seeking}

First, we assessed the differences between male and female rats in the context-induced reinstatement of alcohol-seeking behavior. For that, we used a total of 26 rats (i.e., 13 male and 13 female rats). The control group (A-B-B) underwent alcohol self-administration training in context $\mathrm{A}$, extinction training in context $\mathrm{B}$, and reinstatement testing in context B. The Renewal (A-B-A) group underwent alcohol self-administration training in context $\mathrm{A}$, extinction training in context $\mathrm{B}$, and reinstatement testing in context $\mathrm{A}(30 \mathrm{~min})$. The numbers of rats per group on the test day were as follows: context B ( 6 male and 7 female rats) and context A (7 male and 6 female rats). Rats in the Control and 

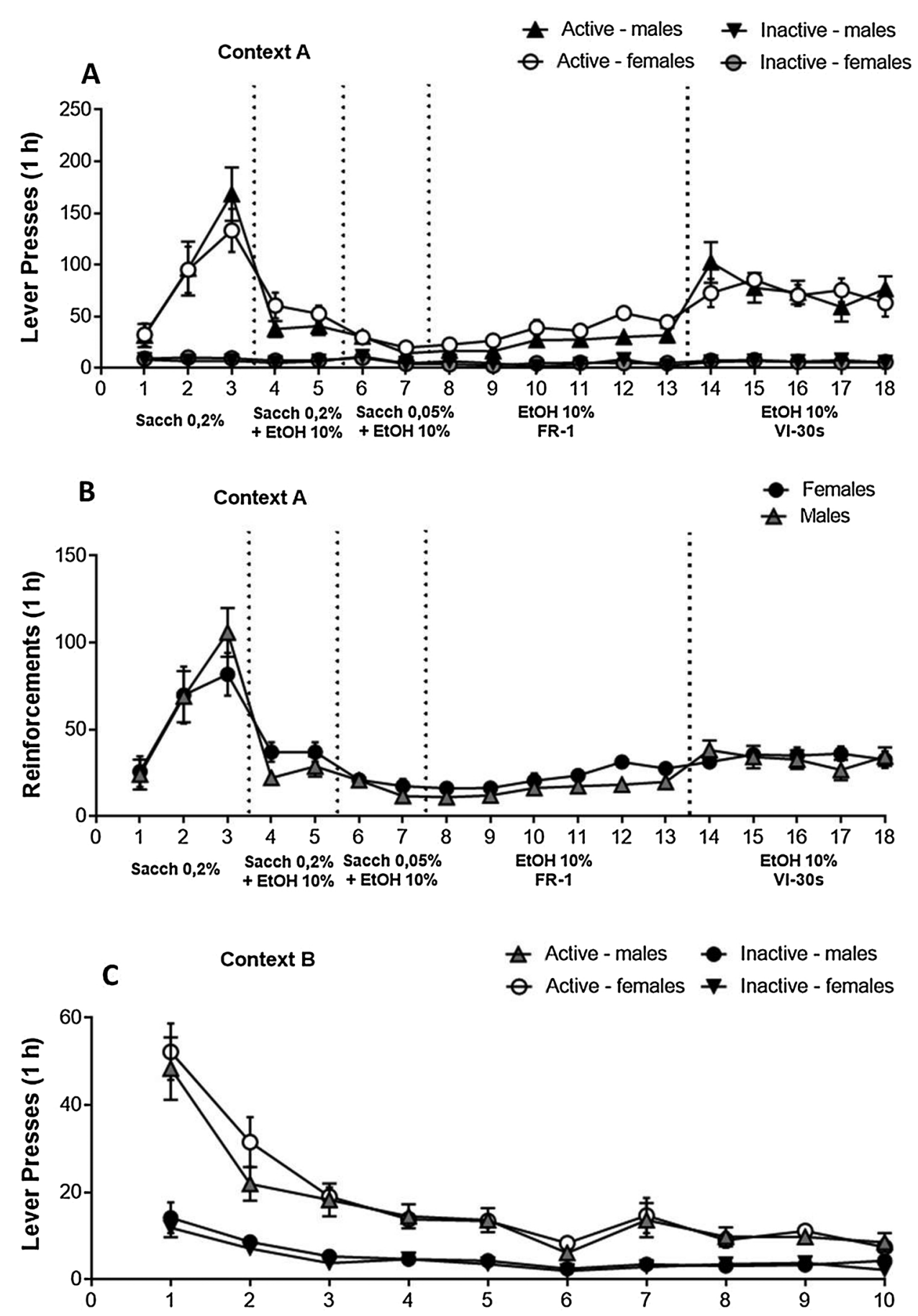

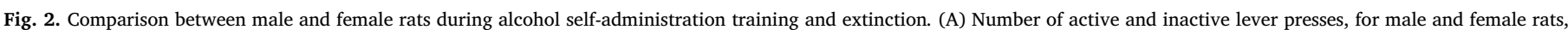

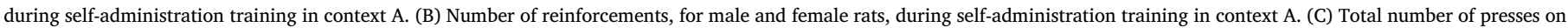

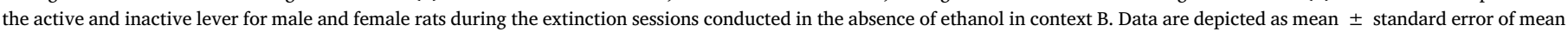
(SEM), $\mathrm{n}=13$ per group.

Renewal groups were matched for their alcohol intake and number of active lever presses during training and extinction.

We used immunohistochemistry to characterize the involvement of the OFC with context-induced reinstatement of alcohol operant selfadministration.

The rats were anesthetized with tribromoethanol $\left(250 \mathrm{mg} \mathrm{kg}^{-1}\right.$, i.p.) $60 \mathrm{~min}$ after the end of the reinstatement test and perfused with $100 \mathrm{ml}$ of phosphate-buffered saline (PBS) followed by $400 \mathrm{ml}$ of $4 \%$ paraformaldehyde.

The brains were post-fixed in paraformaldehyde for $90 \mathrm{~min}$ and transferred to $30 \%$ sucrose in PBS solution, at $4^{\circ} \mathrm{C}$, for $2-3$ days. The brains were frozen in powdered dry ice and kept at $-80^{\circ} \mathrm{C}$ until sectioning. Coronal sections were cut, at a thickness of $40 \mu \mathrm{m}$, between Bregma +3.7 and $+2.7 \mathrm{~mm}$ (Paxinos and Watson, 2005). Free-floating sections were washed three times in PBS, blocked with 3\% normal goat serum (NGS) in PBS with $0.25 \%$ Triton X-100 (PBS-Tx), and incubated for $24 \mathrm{~h}$ at $4{ }^{\circ} \mathrm{C}$ with anti-Fos antibody (sc-52; Santa Cruz Biotechnology) diluted 1:4000 in blocking solution. Sections were washed again with PBS and incubated for $2 \mathrm{~h}$ in biotinylated goat anti-rabbit secondary antibody (1:400; Vector Laboratories) in PBS-Tx and $1 \%$ NGS. After washing in PBS, the sections were incubated for $1 \mathrm{~h}$ in avidin-biotin-peroxidase complex (ABC Elite kit, PK-6100; Vector 


\section{A Two-bottle choice}

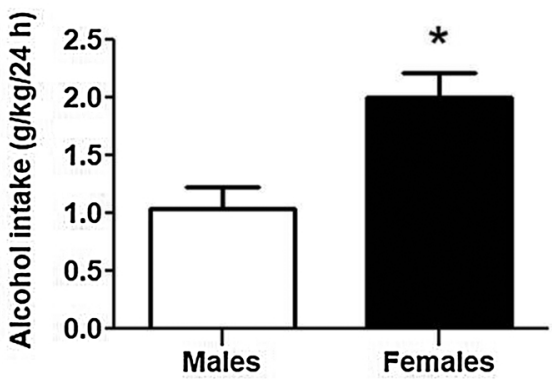

B

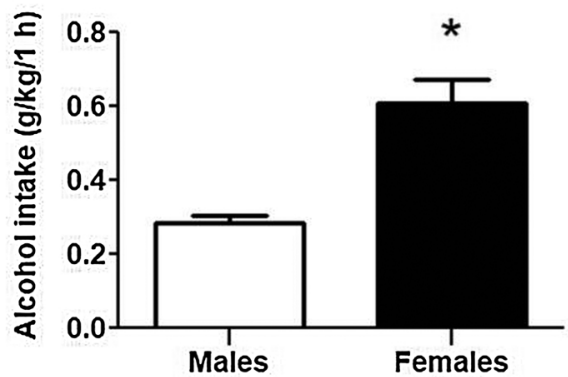

D Males

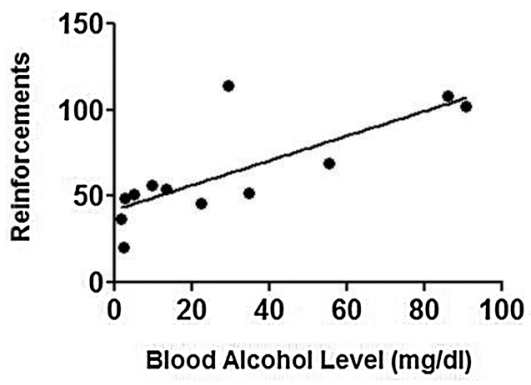

C

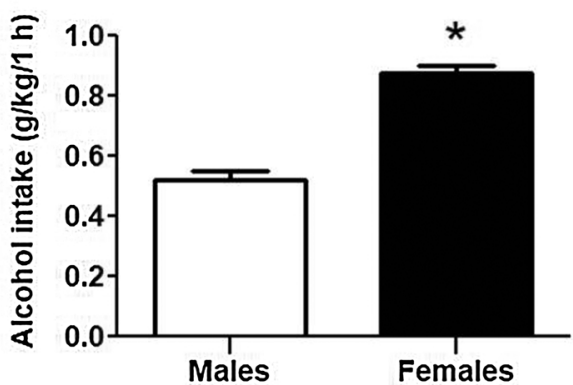

E Females

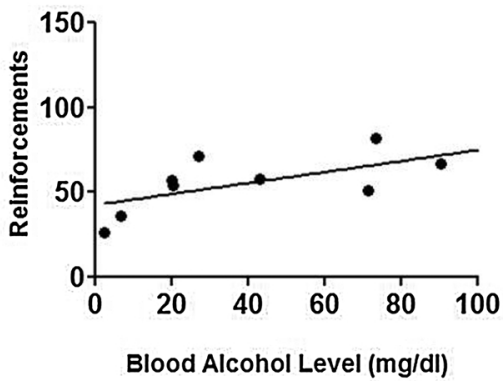

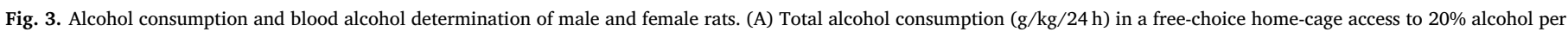

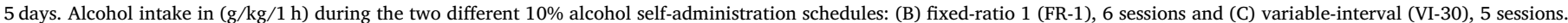

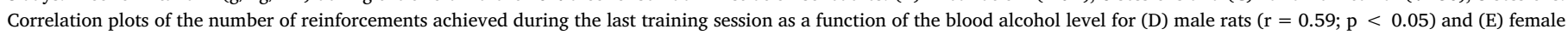
rats $(\mathrm{r}=0.47 ; \mathrm{p}<0.05)$. Data represented as mean \pm standard error of mean (SEM); * different from male rats, $\mathrm{p}<0.05, \mathrm{n}=10-13$ per group.

Laboratories) in PBS containing 0.5\% Triton X-100. Finally, sections were washed in PBS and developed in 3,3'-diaminobenzidine for approximately $3 \mathrm{~min}$, transferred into PBS, and mounted onto chromalum-gelatin-coated slides. Once dry, the slides were dehydrated through a graded series of alcohol and cleared with xylol (LabSynth, SP, Brazil) before being coverslipped with Permount (Sigma-Aldrich, St. Louis).

Bright-field images of Fos immunoreactivity in the OFC were captured using a CCD camera (Coolsnap Photometrics, Roper Scientific Inc) and Qimaging Exi Aqua attached to a Zeiss Axioskop 2 microscope. Images for counting labeled cells were captured at $100 \times$ magnification. Labeled cells from 3 to 4 hemispheres per rat were automatically counted using IPLab software for Macintosh, version 3.9.4 r5 (Scanalytics Inc) and iVision for Macintosh, version 4.0.15 (Biovision). Counts from all images from each rat were averaged so that each rat was an $\mathrm{n}$ of 1 .
2.9. Experiment 2: effect of pharmacological inactivation of orbital frontal cortex neurons on context-induced the reinstatement of alcohol seeking

We reversibly deactivated the OFC using muscimol and baclofen (Bossert et al., 2011; Cruz et al., 2014; Marchant et al., 2014) to determine the causal role of OFC in context-induced reinstatement of alcohol-seeking behavior. A total of 33 male $(n=15)$ and female $(n=18)$ rats were anesthetized and permanent bilateral guide cannulas were implanted into the OFC. On the test day, the rats received bilateral injections $(0.5 \mu \mathrm{l}$ per side) of either muscimol + baclofen $(0.06+0.6 \mathrm{mM})$ (Tocris) dissolved in sterile saline or its vehicle. The rats were injected $15 \mathrm{~min}$ prior to the reinstatement tests as described above. The numbers of rats per group on the test day were as follows: saline-context B $(\mathrm{n}=8)$; baclofen + muscimol-context B $(\mathrm{n}=7)$; saline-context A $(n=7)$; baclofen + muscimol-context A ( $n=11)$. The male and female rats were spread equally across the groups.

To eliminate the possibility that the effect of baclofen + muscimol 

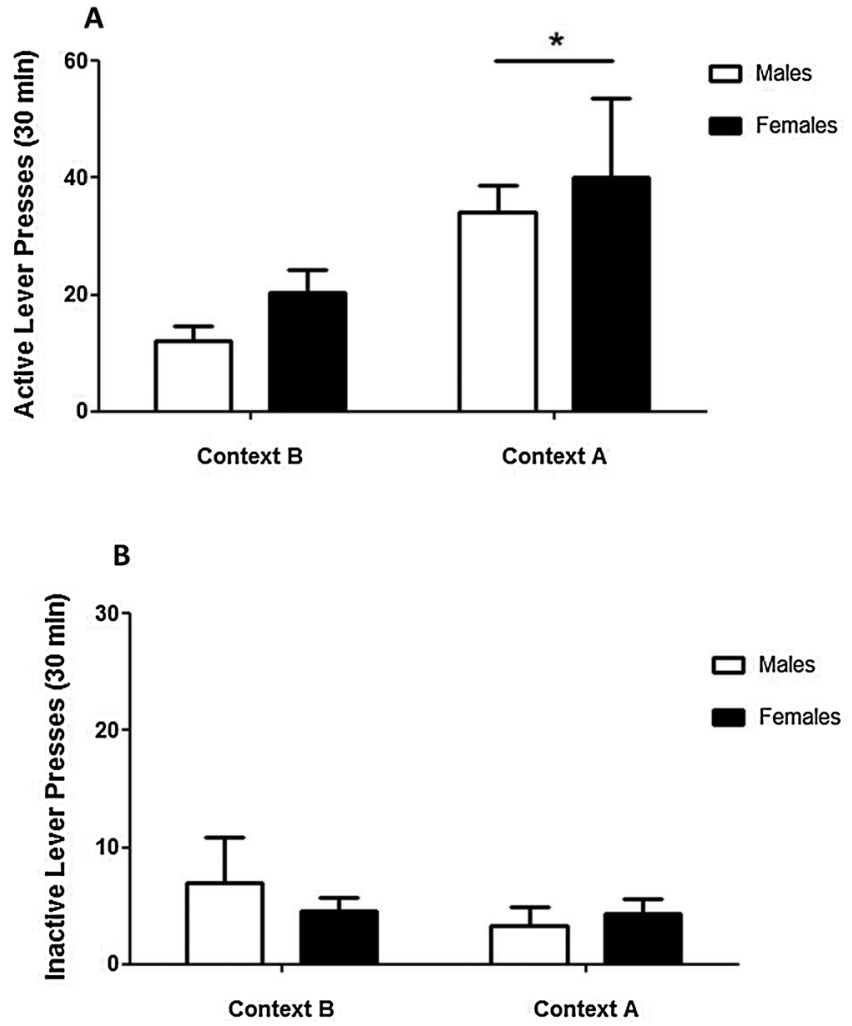

Fig. 4. Comparison between male and female rats in context-induced reinstatement of alcohol-seeking. Total number of (A) active and (B) inactive lever presses in rats tested in the Context B or Context A during reinstatement test. Data are showed as mean \pm standard error of mean (SEM). * different from Context B, $\mathrm{p}<0.05, \mathrm{n}=6-7$ per group.

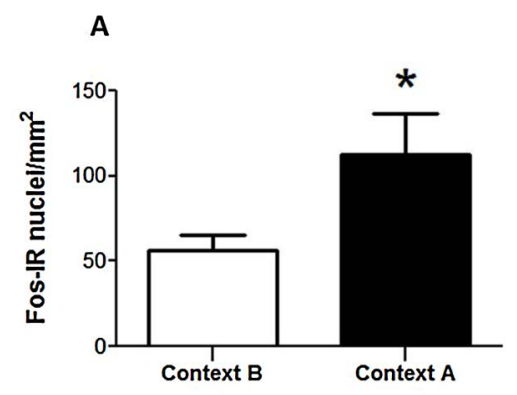

B

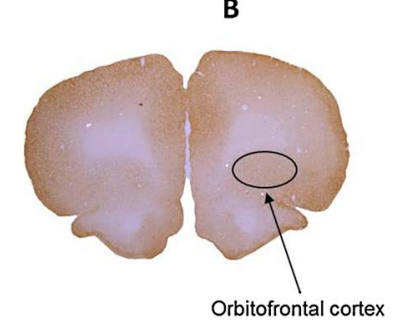

Context B

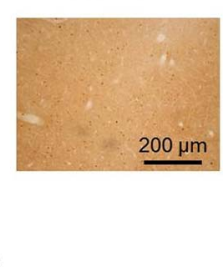

Context A

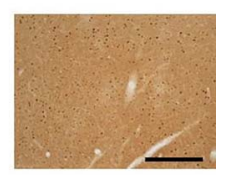

Fig. 5. Context-induced reinstatement of alcohol-seeking is associated with Fos induction in orbitofrontal cortex. (A) Number of Fos-IR nuclei per $\mathrm{mm}^{2}$ in orbitofrontal cortex. Data depicted as mean \pm standard error of mean (SEM). * different from context B p $<0.05$, $\mathrm{n}=6$ per group. (B) Area used for quantifying Fos-IR neurons in the orbitofrontal cortex of rats. Fos-IR nuclei in orbitofrontal cortex captured at 100x magnification of rats that were exposed to (C) context B and (D) context A in the test day. on test day was due to motor deficits, 13 rats were trained after completion of this experiment to lever-press for $0.2 \%$ saccharin solution on a FR-1, 20-s timeout reinforcement schedule for a 30-min session test. Subsequently, we assessed the effect of vehicle or baclofen + muscimol injections into OFC on saccharin-maintained responses. The experimental design is outlined in Fig. 6A.

At the end of the experiments, the rats were anesthetized, perfused, and their brains were removed and kept in $10 \%$ formaldehyde for $48 \mathrm{~h}$. The rat brains were then sectioned at $40 \mu \mathrm{m}$, using a Leica cryostat, stained with cresyl violet, and imaged using light microscopy to verify the cannula placements.

\subsection{Statistical analyses}

The behavioral data were analyzed using an analysis of variance (ANOVA). ANOVAs indicating interaction effects $(\mathrm{p}<0.05)$ were followed by Newman-Keuls post-hoc tests. Molecular data and sex differences in alcohol consumption were analyzed using a Student's $t$-test. The data were analyzed using Statistic StatSoft program, and statistical significance was set at $\mathrm{p}<0.05$. The dependent measures and factors used in the statistical analyses are described in the results section below. For correlation analyses between reinforcement and BAL we used the linear regression function of Graphpad Prism software.

In addition, we used a different Generalized Estimation Equations (GEE) during the training and extinction sessions, which allowed the assessment of the effect of time and sex on number of reinforcements and active and inactive lever presses. These data were analyzed using the SPSS Statistics 17 software. We also assessed the variability between five different manipulations and the within-subject variance. The robust estimator (Huber-White/sandwich estimator) under correlation matrix structure of an auto-regressive of first order was used. Five different periods of self-administration were analyzed separately (i.e., saccharin training: 0 to 3rd session; saccharin + EtOH training: 4 th to 7 th session; EtOH/FR-1 training: 8th to 13th session; EtOH/VI-30 training: 14th to 18th session; and 10 sessions of extinction).

\section{Results}

\subsection{Experiment 1: comparison between male and female rats during training, extinction, and reinstatement test}

Fig. 2A and B depict the mean \pm standard error of mean (SEM) number of active or inactive lever presses and reinforcements for alcohol, respectively, during the training phase in context A for the male and female rats used in experiment 1 . The rats showed consistent alcohol self-administration, as indicated by the increase in active lever presses during the VI-30 sessions. Fig. 2C depicts the mean \pm SEM number of lever presses on the previously active and inactive levers during the first 10 extinction sessions in context $\mathrm{B}$. As expected, the active lever presses decreased over time.

During the saccharin training, a significant effect of time on active lever presses $(b=59.51, p<0.001)$ and reinforcements $(b=32.93$, $\mathrm{p}<0.001$ ) was observed. This indicated the increase of active lever presses and reinforcements during this period. No statistical differences were observed between the sexes, and there was no significant interaction between sex and time.

A significant effect of time on active lever presses $(b=-11.42$, $\mathrm{p}<0.001)$ and reinforcements $(\mathrm{b}=-5.36, \mathrm{p}<0.001)$ was also observed during the saccharin + EtOH training. This indicated the decrease in active lever presses and reinforcements over time. There were no statistical differences between the sexes and no significant interaction between sex and time.

Significant effects of time $(b=4.18, \quad p<0.003)$ and sex $(b=11.78, p<0.001)$ were observed on the active lever presses during EtOH FR-1. The number of active lever presses increased during this period. The sex analysis demonstrated that female rats had more 
A

\begin{tabular}{|c|c|c|c|c|c|c|}
\hline 1: Home cage & \multicolumn{6}{|c|}{ 2: Context A } \\
\hline $\begin{array}{l}7 \times 24 h \\
\text { sessions }\end{array}$ & $\begin{array}{l}3 \mathrm{x} \text { FR-1 } \\
\text { sessions }\end{array}$ & $\begin{array}{l}2 \mathrm{x} \text { FR-1 } \\
\text { sessions }\end{array}$ & \multicolumn{2}{|c|}{$\begin{array}{l}2 \mathrm{x} \text { FR-1 } \\
\text { sessions }\end{array}$} & $\begin{array}{l}6 \mathrm{x} \text { FR-1 } \\
\text { sessions }\end{array}$ & $\begin{array}{l}5 \mathrm{x} \text { VI-30s } \\
\text { sessions }\end{array}$ \\
\hline $\begin{array}{l}\text { Two-bottle choice } \\
20 \% \text { alcohol vs. water }\end{array}$ & Saccharin $0.2 \%$ & $\begin{array}{c}\text { Saccharin } 0.2 \% \\
+ \\
\text { Alcohol } 10 \%\end{array}$ & \multicolumn{2}{|c|}{$\begin{array}{c}\text { Saccharin } \\
+ \\
+ \\
\text { Alcohol } 10 \%\end{array}$} & Alcohol 10\% & Alcohol 10\% \\
\hline \multirow{3}{*}{$\begin{array}{c}\text { 3: Intracranial } \\
\text { Surgery }\end{array}$} & 4: Context A & \multicolumn{2}{|c|}{ 5: Context B } & \multicolumn{2}{|c|}{ 6: Test day } & 7: Sacch Test \\
\hline & $2 \mathrm{x}$ VI- 30 s sessions & \multicolumn{2}{|c|}{$10 \mathrm{x}$ VI-30s sessions } & \multicolumn{2}{|c|}{$1 \mathrm{x}$ VI-30s session } & 1x FR-1 session \\
\hline & Alcohol $10 \%$ & \multicolumn{2}{|l|}{$\begin{array}{l}\text { Extinction } \\
\text { conditions }\end{array}$} & \multicolumn{2}{|c|}{$\begin{array}{l}\text { Extinction conditions } \\
\text { in context } \mathrm{A} \text { or } \mathrm{B}\end{array}$} & $\begin{array}{c}\text { Saccharin } 0.2 \% \\
\text { Independent context }\end{array}$ \\
\hline
\end{tabular}

* Sacch (saccharin)
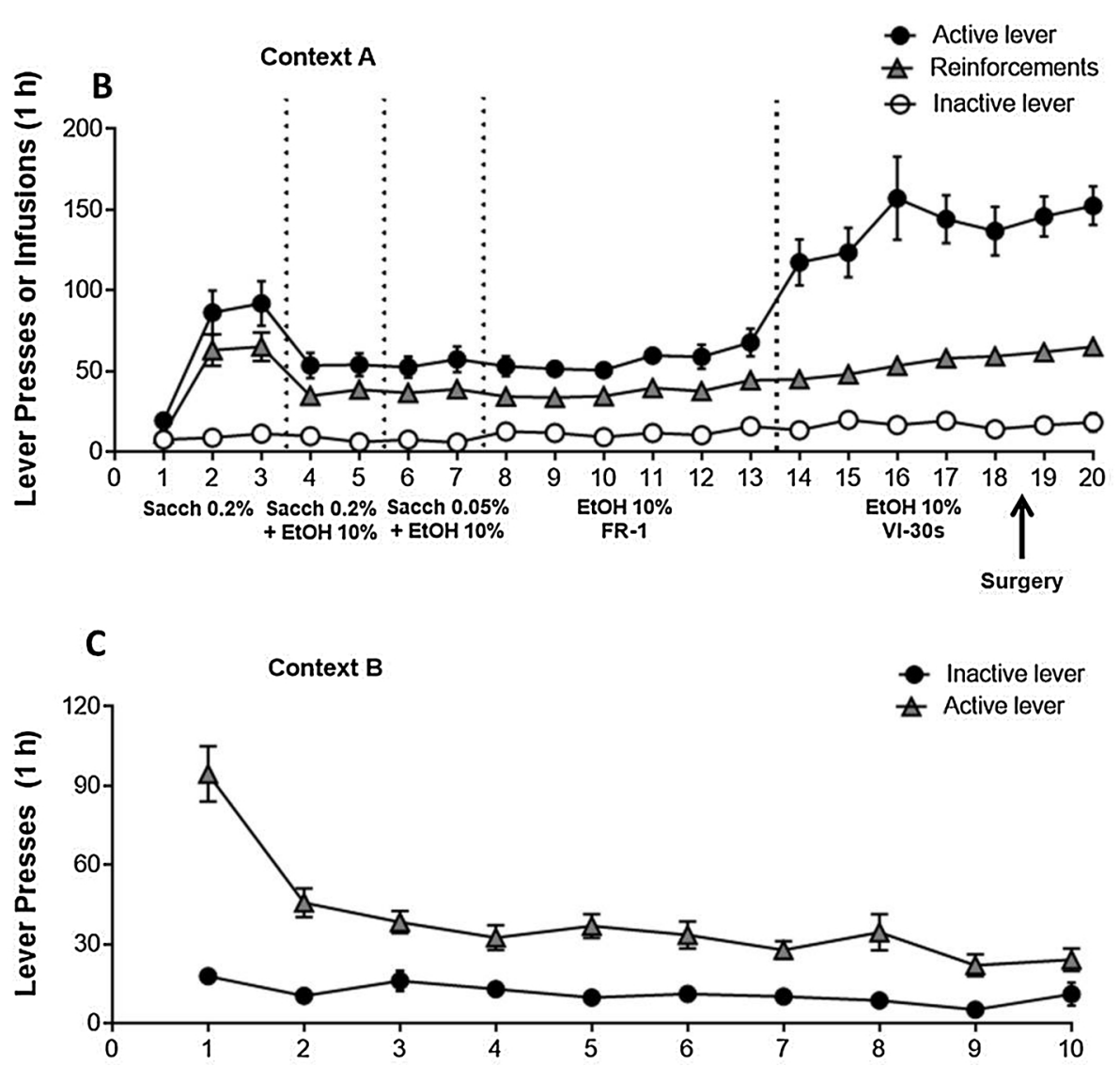

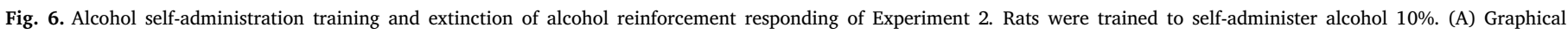

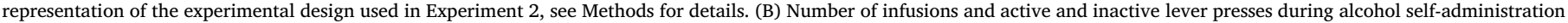

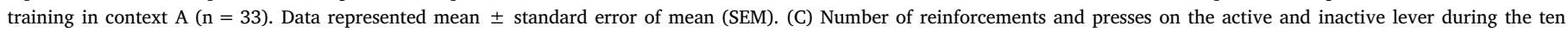
extinction sessions conducted in the absence of ethanol in context B. Data represented mean \pm SEM.

active lever presses than the male rats. Further, time $(b=1.89$, $\mathrm{p}<0.003)$ and sex $(\mathrm{b}=6.58, \mathrm{p}<0.001)$ also had a significant effect on the number of reinforcements, indicating that rats increased the number of reinforcements during EtOH/FR-1 training, and female rats had more reinforcements than male rats. Further, a significant interaction between sex and time was observed for inactive lever presses, which indicated that the female rats pressed the inactive lever fewer times than the male rats.

Statistical analyses of VI-30 interval data demonstrated the effect of time alone $(b=-5.03, p<0.003)$ on active lever presses, demonstrating a decrease of presses over time. No statistical differences were observed between the sexes; there was no significant interaction between sex and time.
During the extinction phase, time had a significant effect on active $(b=-3.76, p<0.001)$ and inactive $(b=-0.86, p<0.001)$ lever presses. A decrease in the numbers of active and inactive lever presses were observed. There were not significant differences between the sexes and, there was no significant interaction between the sex and time factors.

In summary, the data indicated that the self-administration responses and reinforces during the saccharin, ethanol+ saccharin, ethanol IV-30 training, and extinction sessions did not significantly differ between male and female rats. Female rats, however, showed a higher number of active lever presses and ethanol reinforcements compared to those of the male rats during the ETOH/FR-1 training.

Fig. 3 depicts the mean \pm SEM total alcohol consumption $(\mathrm{g} / \mathrm{kg})$ 
Blood alcohol determination

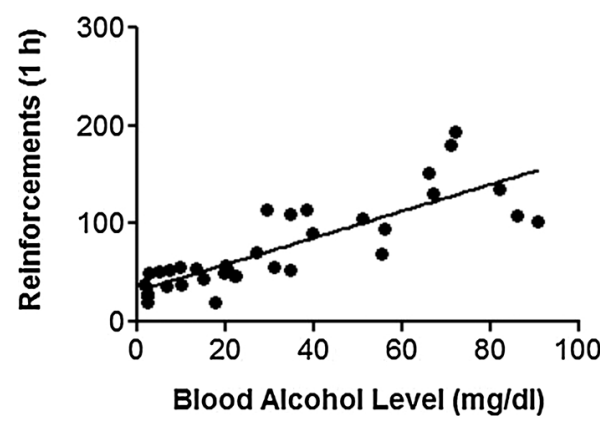

Fig. 7. Blood alcohol determination of Experiment 2. Immediately after the end of the last VI-30 s session, blood samples $(100 \mu \mathrm{l})$ were collected from the tip of the tail of rats $(\mathrm{n}=35)$. The graph depicts correlation plots of the number of reinforcements achieved during the last training session as a function of the blood alcohol level $(r=0.68$, $\mathrm{p}<0.05)$.

during the two-bottle choice paradigm (Fig. 3A), operant self-administration in FR-1 (Fig. 3B), and operant self-administration in VI-30 (Fig. 3C). Fig. 3D and E show the correlation between the number of reinforcements achieved during the last VI-30 training session and the blood alcohol levels in male and female rats, respectively.

Alcohol consumption was higher in female rats than in male rats during exposure to the two-bottle choice test $\left(\mathrm{t}_{(8)}=-3.29\right.$; $\mathrm{p}<0.05)$, self-administration training in FR-1 $\left(\mathrm{t}_{(10)}=-4.77\right.$; $\mathrm{p}<0.05)$, and VI-30 $\left(\mathrm{t}_{(8)}=-8.74 ; \mathrm{p}<0.05\right)$.

Immediately after the end of the last VI-30-s session, blood samples $(100 \mu \mathrm{l})$ were collected from the tip of the tail of male and female rats. A significant correlation between the number of reinforcements and blood alcohol level for male $(r=0.59 ; p<0.05)$ and female $(r=0.47$; $\mathrm{p}<0.05$ ) rats was observed.

On the test day, we assessed context-induced reinstatement of alcohol-seeking behavior by assessing non-reinforced lever presses in Context A versus Context B. Fig. 4A and B depict the mean \pm SEM number of active and inactive lever presses, respectively, during the test day for male and female rats. For active lever presses, there was a significant difference between context (A vs. $\mathrm{B}: \mathrm{F}_{(1.22)}=8.50$, $\mathrm{p}<0.05)$ but not between sex $\left(\mathrm{F}_{(1.22)}=1.02\right.$, $\left.\mathrm{p}>0.05\right)$. There was also no significant interaction between context and $\operatorname{sex}\left(\mathrm{F}_{(1.22)}=0.02\right.$, $\mathrm{p}>0.05$ ). The results indicate that exposure to context $\mathrm{A}$, but not context $\mathrm{B}$, increased active non-reinforced lever pressing independent of sex.

To assess whether the difference between male and female rats observed during the ETOH/FR-1 training could influence the reinstatement test, we analyzed the active lever-press data during the test day using a two-way ANCOVA with between-subject factors of context (A, B) and sex (male, female) and the covariate of average of active lever-presses during the 6 days of FR-1. This analysis did not show a significant interaction between context and $\operatorname{sex}\left(\mathrm{F}_{(1.21)}=0.012\right.$, $\mathrm{p}>0.05$ ). The lever presses of male and female rats during the ETOH/ FR-1 training did not have an effect on active lever-presses on the test day.

Since no significant differences were observed between male and female rats in the reinstatement test, we grouped male and female rats for Fos-immunoreactive analysis and for experiment 2 .

We aimed to determine whether context-induced reinstatement of alcohol-seeking behavior was associated with increased Fos-immunoreactive nuclei (Fos-IR) in the OFC. We analyzed Fos expression in the OFC using Context (A, B) as the between-subject factor. We also determined the proportion of all OFC neurons expressing Fos during the reinstatement test using double-labeling immunohistochemistry.

Exposure to the Alcohol Context A increased the number of Fos-IR nuclei in the OFC (Fig. 5A). Fos-IR levels were higher in Context A than in Context B $\left(\mathrm{t}_{(10)}=2.23 ; \mathrm{p}<0.05\right)$.

3.2. Experiment 2: baclofen + muscimol inactivation of orbitofrontal cortex decreased context-induced reinstatement of alcohol-seeking

Fig. 6B depicts the mean \pm SEM number of alcohol reinforcements and active and inactive lever presses during the training phase in Context A. The rats showed consistent alcohol self-administration as indicated by the increase in active lever presses during the VI-30 session. Fig. $6 \mathrm{C}$ depicts the mean \pm SEM number of previously active and inactive lever during the 10 extinction sessions in context B. As expected, the number of active lever presses decreased over time. Fig. 7 shows the significant correlation between the number of reinforcements achieved during the last VI-30 training session and the blood alcohol level $(r=0.68 ; \mathrm{p}<0.05)$.

The reversibly inactivating procedure with baclofen + muscimol was used to determine the OFC causal role in context-induced reinstatement of alcohol-seeking behavior. A two-way ANOVA demonstrated the significant interaction between Context (A, B) and Drug (Vehicle, Muscimol + Baclofen) for active lever presses $\left(\mathrm{F}_{(1.28)}=8.75\right.$, $\mathrm{p}<0.05)$. Post-hoc analysis indicated that the muscimol + baclofen injections into the OFC attenuated active lever pressing in Context A, but not during Extinction Context B. There was no significant interaction between Context (A, B) and Drug (Vehicle, Muscimol + Baclofen) for inactive lever presses $\left(\mathrm{F}_{(1.28)}=3.06, \mathrm{p}>0.05\right)$ (Fig. $8 \mathrm{~A}$ and $\mathrm{B}$ ).

Finally, to eliminate the possibility that the effect of injecting muscimol + baclofen into the OFC were due to motor deficits, we retrained 9 rats that previously participated in Experiment 3 to lever press for $0.2 \%$ saccharin solution. After a stable response was observed, we determined the effect of muscimol + baclofen or vehicle injections into the OFC on high-rate operant response for saccharin. A two-way ANOVA revealed a significant difference between Lever (Active vs. Inactive: $\left.F_{(1.22)}=21.33, p<0.05\right)$ but did not indicate a significant interaction between Lever (Active, Inactive) and Drug (Vehicle, Muscimol + Baclofen; $\left.\mathrm{F}_{(1.14)}=0.00021, \mathrm{p}>0.05\right)$. Local inactivation of the OFC with muscimol + baclofen had no effect on the high-rate saccharin response, indicating that their effects on context-induced reinstatement of alcohol-seeking behavior were not due to motor deficits (Fig. 8D).

\section{Discussion}

In the current study, we investigated the role of the OFC in contextinduced reinstatement of alcohol-seeking behavior. Our results corroborated with previous reports (Marchant et al., 2013; Willcocks and McNally, 2013) demonstrating that alcohol-seeking behavior was induced by re-exposure to the alcohol-associated context after the extinction of drug self-administration in a different context. We demonstrated that the context-induced reinstatement of alcohol seeking was associated with increased Fos expression in the OFC. Reversible inactivation of OFC attenuated context-induced reinstatement of alcoholseeking behavior. There was no difference in the observed context-induced reinstatement of alcohol-seeking behavior between male and female rats.

Context-induced reinstatement of extinguished drug seeking behavior has been observed for several drugs of abuse, including cocaine (Cruz et al., 2014; Lasseter et al., 2009), heroin (Bossert et al., 2011), nicotine (Diergaarde et al., 2008), and alcohol (Marchant et al., 2013; Willcocks and McNally, 2013). Our results corroborated with clinical studies indicating that a context which was previously associated with alcohol use often provoked relapse during abstinence (Litt and Cooney, 2000; O'Brien et al., 1990).

We observed that female rats showed higher alcohol consumption than males $(\mathrm{g} / \mathrm{kg})$ when exposed for 5 days in a two-bottle choice paradigm. Female rats also presented greater active lever presses, reinforcements, and alcohol intake $(\mathrm{g} / \mathrm{kg})$ during FR-1 training compared 
A

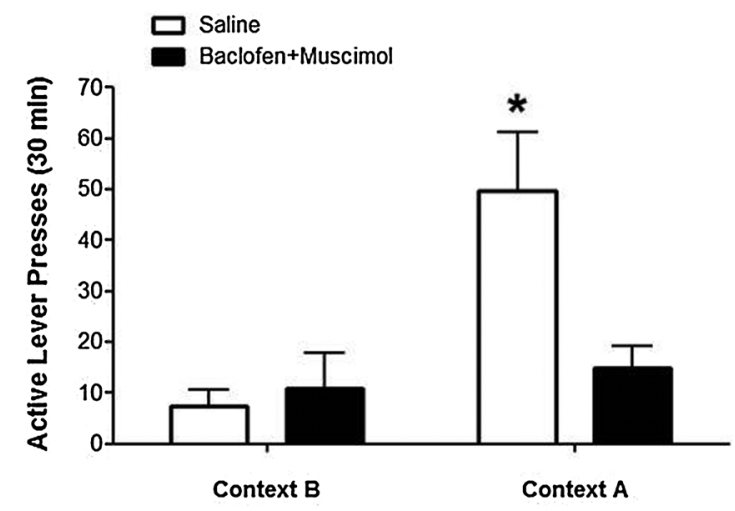

B

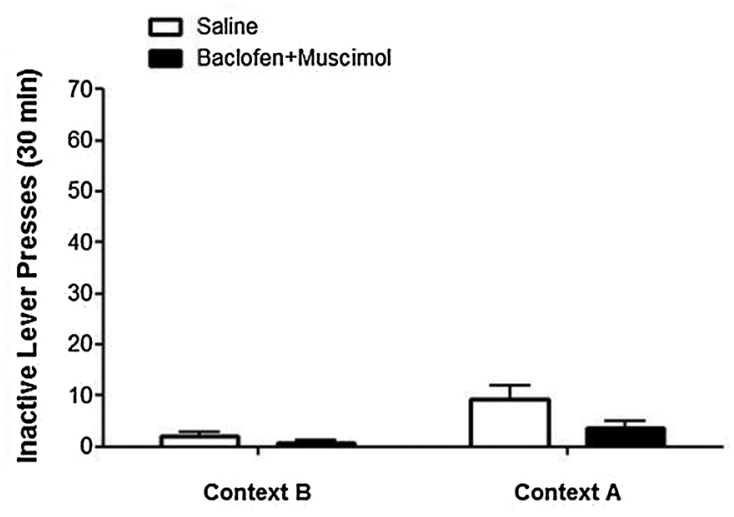

C

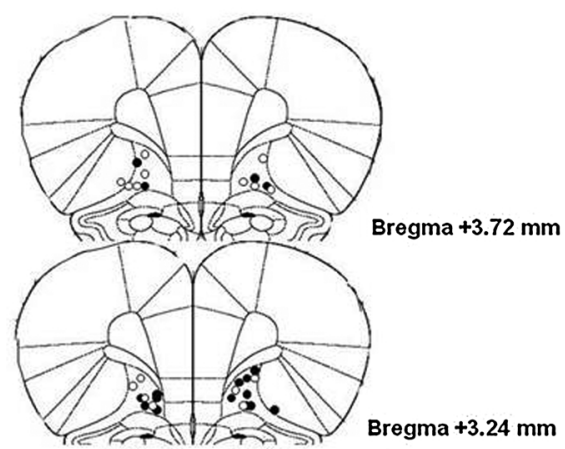

D
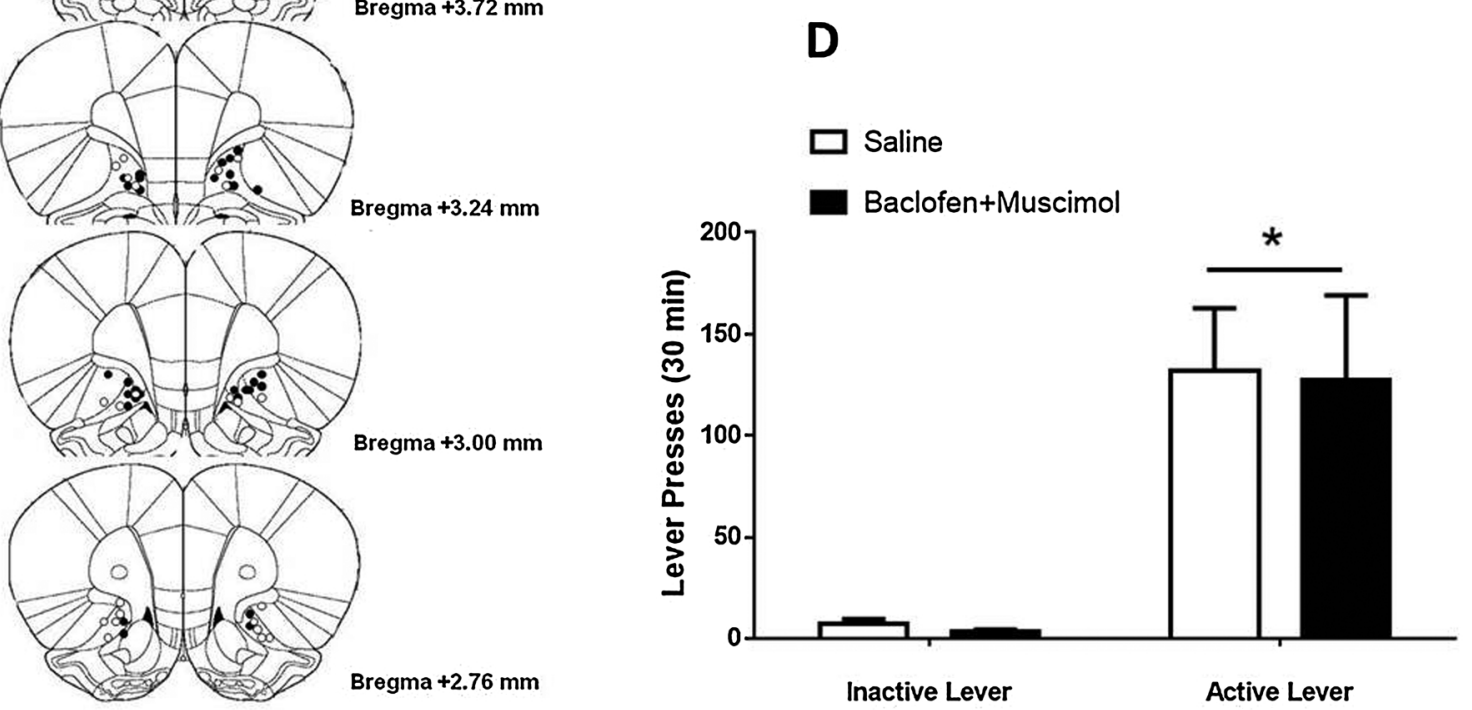

Saline

Baclofen+Muscimol

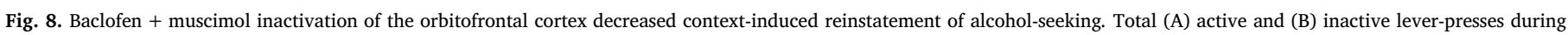

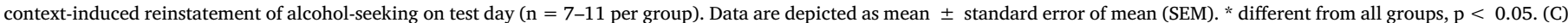

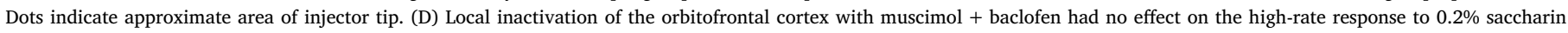

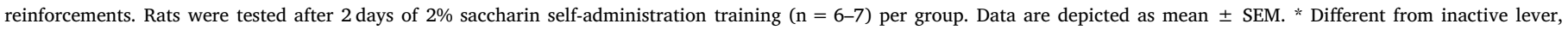
$\mathrm{p}<0.05$.

to male rats. Throughout the VI-30 phase, male and female rats showed similar numbers of active lever presses and reinforcements; the female rats, however, showed greater alcohol intake $(\mathrm{g} / \mathrm{kg})$ than the male rats. This finding is supported by several previous studies in which females showed more alcohol intake than males (Almeida et al., 1998; Gamsby et al., 2013; Juarez and Barrios de Tomasi, 1999; Lancaster and Spiegel, 1992; Maldonado-Devincci et al., 2010; Walker et al., 2008). However, some previous studies demonstrated similar alcohol consumption between male and female rats (Schramm-Sapyta et al., 2014; van Haaren and Anderson, 1994; Varlinskaya and Spear, 2015). Further, Randall et al. (2017), observed that although male rats tended to have greater alcohol-reinforced responses, female rats showed greater alcohol intake (g/kg) (Randall et al., 2017).

During the assessment of extinction and relapse-like behavior, there 
was no sex differences in the number of lever presses throughout extinction or the context-induced reinstatement test. These findings corroborated with the study conducted by Randall et al. (2017), in which no differences in the responses during the extinction sessions and reinstatement of alcohol seeking test were observed between male and female rats.

Few studies have investigated sex differences in the reinstatement of alcohol seeking in rats. For instance, McKinzie et al. (1998) did not find any sex differences in the reinstatement of alcohol-seeking behavior and alcohol consumption when measured after a long period of alcohol deprivation. In contrast, Bertholomey et al. (2016) demonstrated that female rats were more sensitive to yohimbine-induced reinstatement of alcohol-seeking behavior than the male rats.

Addictive drugs modify brain circuits that are crucial for the normal control of behaviors (Kauer and Malenka, 2007; Koob and Volkow, 2010; Schoenbaum et al., 2006). Numerous studies have demonstrated that drug seeking and drug relapse are mediated by drug-induced changes in the OFC (Jentsch and Taylor, 1999; London et al., 2000; Schoenbaum et al., 2006; Volkow and Fowler, 2000). However, the majority of these studies investigated the involvement of the OFC in psychostimulant-induced addiction-like behaviors (London et al., 2004; Stapleton et al., 1995). For instance, brain imaging studies revealed that drug-related cues increase the activation of the OFC in cocaine, methamphetamine, and heroin users (London et al., 2004; Stapleton et al., 1995; Volkow et al., 2001; Volkow and Fowler, 2000; Volkow et al., 1991). To our knowledge our study is the first to demonstrate the involvement of the OFC in context-induced reinstatement of alcoholseeking behavior.

Immunohistochemistry studies have suggested a correlation between cue- or context-induced drug seeking and OFC activation. For instance, it was demonstrated that exposure to cues previously paired with cocaine or heroin administration increased the expression of Zif268 and c-Fos (neuronal activation markers) in the OFC (Fanous et al., 2012; Morgan and Curran, 1991; Thomas et al., 2003).

Functional studies also confirmed the involvement of OFC in contextual cues that induce drug-seeking behaviors. Lasseter et al. (2009) reported that reversible inactivation of the OFC using a mixture of GABAergic agonists, i.e., muscimol and baclofen, impaired context-induced reinstatement of cocaine-seeking behavior in rats. Similarly, Fanous et al. (2012) demonstrated that injections of baclofen + muscimol into the OFC decreased cue-induced heroin seeking.

We speculated that the role of the OFC in context-induced reinstatement of drug-seeking could be attributed to its involvement in memory processes (Moorman and Aston-Jones, 2014). Lasseter et al. (2011) demonstrated that the BLA and lateral OFC are critical elements of the neural circuitry that regulate drug context-induced reinstatement of cocaine-seeking behavior. For example, re-exposure to alcohol-associated context increased c-Fos mRNA expression in the BLA, suggesting that this brain region plays a role in context-induced reinstatement of alcohol-seeking behavior (Marinelli et al., 2007). Further, OFC neurons fired in anticipation of the presentation of either reward or punishment during an odor-discrimination task (Schoenbaum et al., 1998; Schoenbaum et al., 2003). Moreover, evidence has demonstrated that the OFC plays an important role in the acquisition and expression of Pavlovian stimulus-outcome associations (Ostlund and Balleine, 2007; Panayi and Killcross, 2014). Overall, these findings indicated that neural activity of the OFC and associated limbic areas plays a role in the memory or motivational significance of associated stimuli to guide goal-directed behavior.

In conclusion, although male and female Long-Evans rats showed differences in alcohol intake and responses during the self-administration training, no differences in number of lever presses was observed during the extinction or reinstatement of alcohol-seeking behavior. In addition, the functional inactivation of the OFC prevented reinstatement of an extinguished response to alcohol. Thus, we demonstrated that the OFC is required for context-induced reinstatement of alcohol- seeking behavior.

\section{Contributors}

P.C.B., R.M.L., P.E.C.O., P.P., H.C.M., C.S.P and F.C.C. designed research; P.C.B., R.M.L., P.E.C.O., P.P., and F.C.C., performed research; F.C.C. and C.S.P contributed unpublished reagents/analytic tools; P.C.B, C.S.P, H.C.M., and F.C.C analyzed data; P.C.B, H.C.M., C.S.P and F.C.C. wrote the paper. We confirm that the manuscript has been read and approved by all named authors; there are no other persons who satisfied the criteria for authorship but are not listed. We further confirm that the order of authors listed in the manuscript has been approved by all of us.

\section{Role of funding source}

This research was supported by São Paulo Research Foundation FAPESP (2013/24896-2) and National Council for Scientific and Technological Development-CNPq (164060/2014-6).

\section{Conflict of interest}

No conflict declared.

\section{Acknowledgement}

We are thankful to Bruce T. Hope for scientific support.

\section{References}

Almeida, O.F., Shoaib, M., Deicke, J., Fischer, D., Darwish, M.H., Patchev, V.K., 1998 Gender differences in ethanol preference and ingestion in rats. The role of the gonadal steroid environment. J. Clin. Invest. 101, 2677-2685.

Bertholomey, M.L., Nagarajan, V., Torregrossa, M.M., 2016. Sex differences in reinstatement of alcohol seeking in response to cues and yohimbine in rats with and without a history of adolescent corticosterone exposure. Psychopharmacology 233, 2277-2287.

Bossert, J.M., Stern, A.L., Theberge, F.R., Cifani, C., Koya, E., Hope, B.T., Shaham, Y., 2011. Ventral medial prefrontal cortex neuronal ensembles mediate context-induced relapse to heroin. Nat. Neurosci. 14, 420-422.

Bouton, M.E., King, D.A., 1983. Contextual control of the extinction of conditioned fear: tests for the associative value of the context. J. Exp. Psychol. Anim. Behav. Process. 9, $248-265$.

Burattini, C., Gill, T.M., Aicardi, G., Janak, P.H., 2006. The ethanol self-administration context as a reinstatement cue: acute effects of naltrexone. Neuroscience 139, 877-887.

Childress, A.R., Mozley, P.D., McElgin, W., Fitzgerald, J., Reivich, M., O'Brien, C.P., 1999. Limbic activation during cue-induced cocaine craving. Am. J. Psychiatry 156, 11-18.

Crombag, H.S., Shaham, Y., 2002. Renewal of drug seeking by contextual cues after prolonged extinction in rats. Behav. Neurosci. 116, 169-173.

Cruz, F.C., Babin, K.R., Leao, R.M., Goldart, E.M., Bossert, J.M., Shaham, Y., Hope, B.T., 2014. Role of nucleus accumbens shell neuronal ensembles in context-induced reinstatement of cocaine-seeking. J. Neurosci. 34, 7437-7446.

Diergaarde, L., de Vries, W., Raaso, H., Schoffelmeer, A.N., De Vries, T.J., 2008. Contextual renewal of nicotine seeking in rats and its suppression by the cannabinoid-1 receptor antagonist Rimonabant (SR141716A). Neuropharmacology 55, $712-716$.

Fanous, S., Goldart, E.M., Theberge, F.R., Bossert, J.M., Shaham, Y., Hope, B.T., 2012 Role of orbitofrontal cortex neuronal ensembles in the expression of incubation of heroin craving. J. Neurosci. 32, 11600-11609.

Fox, H.C., Hong, K.A., Sinha, R., 2008. Difficulties in emotion regulation and impulse control in recently abstinent alcoholics compared with social drinkers. Addict. Behav. 33, 388-394.

Fuchs, R.A., Evans, K.A., Parker, M.P., See, R.E., 2004. Differential involvement of orbitofrontal cortex subregions in conditioned cue-induced and cocaine-primed reinstatement of cocaine seeking in rats. J. Neurosci. 24, 6600-6610.

Gamsby, J.J., Templeton, E.L., Bonvini, L.A., Wang, W., Loros, J.J., Dunlap, J.C., Green, A.I., Gulick, D., 2013. The circadian Per1 and Per2 genes influence alcohol intake reinforcement, and blood alcohol levels. Behav. Brain Res. 249, 15-21.

Grant, S., London, E.D., Newlin, D.B., Villemagne, V.L., Liu, X., Contoreggi, C., Phillips, R.L., Kimes, A.S., Margolin, A., 1996. Activation of memory circuits during cue-elicited cocaine craving. Proceedings of the National Academy of Sciences of the United States of America 93, 12040-12045.

Hamlin, A.S., Newby, J., McNally, G.P., 2007. The neural correlates and role of D1 dopamine receptors in renewal of extinguished alcohol-seeking. Neuroscience 146, $525-536$. 
Janak, P.H., Chaudhri, N., 2010. The potent effect of environmental context on relapse to alcohol-seeking after extinction. Open Addict. J. 3, 76-87.

Jentsch, J.D., Taylor, J.R., 1999. Impulsivity resulting from frontostriatal dysfunction in drug abuse: implications for the control of behavior by reward-related stimuli. Psychopharmacology 146, 373-390.

Juarez, J., Barrios de Tomasi, E., 1999. Sex differences in alcohol drinking patterns during forced and voluntary consumption in rats. Alcohol 19, 15-22.

Kauer, J.A., Malenka, R.C., 2007. Synaptic plasticity and addiction. Nat. Rev. Neurosci. 8, $844-858$

Kilts, C.D., Schweitzer, J.B., Quinn, C.K., Gross, R.E., Faber, T.L., Muhammad, F., Ely, T.D., Hoffman, J.M., Drexler, K.P., 2001. Neural activity related to drug craving in cocaine addiction. Arch. Gen. Psychiatry 58, 334-341.

Koob, G.F., Volkow, N.D., 2010. Neurocircuitry of addiction. Neuropsychopharmacology 217-238.

Lancaster, F.E., Spiegel, K.S., 1992. Sex differences in pattern of drinking. Alcohol 9 , 415-420.

Lasseter, H.C., Ramirez, D.R., Xie, X., Fuchs, R.A., 2009. Involvement of the lateral orbitofrontal cortex in drug context-induced reinstatement of cocaine-seeking behavior in rats. Eur. J. Neurosci. 30, 1370-1381.

Lasseter, H.C., Wells, A.M., Xie, X., Fuchs, R.A., 2011. Interaction of the basolateral amygdala and orbitofrontal cortex is critical for drug context-induced reinstatement of cocaine-seeking behavior in rats. Neuropsychopharmacology 36, 711-720.

Litt, M.D., Cooney, N.L., 2000. Re: comments on reactivity to alcohol-related stimuli in the laboratory and in the field: predictors of craving in treated alcoholics: a reply. Addiction 95, 1107-1108.

London, E.D., Bonson, K.R., Ernst, M., Grant, S., 1999. Brain imaging studies of cocaine abuse: implications for medication development. Crit. Rev. Neurobiol. 13, 227-242.

London, E.D., Ernst, M., Grant, S., Bonson, K., Weinstein, A., 2000. Orbitofrontal cortex and human drug abuse: functional imaging. Cereb. Cortex 10, 334-342.

London, E.D., Simon, S.L., Berman, S.M., Mandelkern, M.A., Lichtman, A.M., Bramen, J., Shinn, A.K., Miotto, K., Learn, J., Dong, Y., Matochik, J.A., Kurian, V., Newton, T., Woods, R., Rawson, R., Ling, W., 2004. Mood disturbances and regional cerebral metabolic abnormalities in recently abstinent methamphetamine abusers. Arch. Gen. Psychiatry 61, 73-84.

Ludwig, A.M., Wikler, A., Stark, L.H., 1974. The first drink: psychobiological aspects of craving. Arch. Gen. Psychiatry 30, 539-547.

Maldonado-Devincci, A.M., Alipour, K.K., Michael, L.A., Kirstein, C.L., 2010. Repeated binge ethanol administration during adolescence enhances voluntary sweetened ethanol intake in young adulthood in male and female rats. Pharmacol. Biochem. Behav. 96, 476-487.

Marchant, N.J., Khuc, T.N., Pickens, C.L., Bonci, A., Shaham, Y., 2013. Context-induced relapse to alcohol seeking after punishment in a rat model. Biol. Psychiatry 73, 256-262.

Marchant, N.J., Rabei, R., Kaganovsky, K., Caprioli, D., Bossert, J.M., Bonci, A., Shaham, Y., 2014. A critical role of lateral hypothalamus in context-induced relapse to alcohol seeking after punishment-imposed abstinence. J. Neurosci. 34, 7447-7457.

Marinelli, P.W., Funk, D., Juzytsch, W., Li, Z., Le, A.D., 2007. Effects of opioid receptor blockade on the renewal of alcohol seeking induced by context: relationship to c-fos mRNA expression. Eur. J. Neurosci. 26, 2815-2823.

McKinzie, D.L., Nowak, K.L., Yorger, L., McBride, W.J., Murphy, J.M., Lumeng, L., Li, T.K., 1998. The alcohol deprivation effect in the alcohol-preferring P rat under freedrinking and operant access conditions. Alcohol. Clin. Exp. Res. 22, 1170-1176.

Moorman, D.E., Aston-Jones, G., 2014. Orbitofrontal cortical neurons encode expectation-driven initiation of reward-seeking. J. Neurosci. 34, 10234-10246.

Morgan, J.I., Curran, T., 1991. Stimulus-transcription coupling in the nervous system: involvement of the inducible proto-oncogenes fos and jun. Annu. Rev. Neurosci. 14,
$421-451$.

O'Brien, C.P., Childress, A.R., McLellan, T., Ehrman, R., 1990. Integrating systemic cue exposure with standard treatment in recovering drug dependent patients. Addict. Behav. 15, 355-365.

Ostlund, S.B., Balleine, B.W., 2007. Orbitofrontal cortex mediates outcome encoding in Pavlovian but not instrumental conditioning. J. Neurosci. 27, 4819-4825.

Panayi, M.C., Killcross, S., 2014. Orbitofrontal cortex inactivation impairs between- but not within-session Pavlovian extinction: an associative analysis. Neurobiol. Learn. Mem. 108, 78-87.

Paxinos, G., Watson, C., 2005. The Rat Brain in Stereotaxic Coordinates. Elsevier Academic Press, Amsterdam.

Randall, P.A., Stewart, R.T., Besheer, J., 2017. Sex differences in alcohol self-administration and relapse-like behavior in Long-Evans rats. Pharmacol. Biochem. Behav. 156, 1-9.

Schoenbaum, G., Shaham, Y., 2008. The role of orbitofrontal cortex in drug addiction: a review of preclinical studies. Biol. Psychiatry 63, 256-262.

Schoenbaum, G., Chiba, A.A., Gallagher, M., 1998. Orbitofrontal cortex and basolateral amygdala encode expected outcomes during learning. Nat. Neurosci. 1, 155-159.

Schoenbaum, G., Setlow, B., Saddoris, M.P., Gallagher, M., 2003. Encoding predicted outcome and acquired value in orbitofrontal cortex during cue sampling depends upon input from basolateral amygdala. Neuron 39, 855-867.

Schoenbaum, G., Roesch, M.R., Stalnaker, T.A., 2006. Orbitofrontal cortex, decisionmaking and drug addiction. Trends Neurosci. 29, 116-124.

Schramm-Sapyta, N.L., Francis, R., MacDonald, A., Keistler, C., O'Neill, L., Kuhn, C.M., 2014. Effect of sex on ethanol consumption and conditioned taste aversion in adolescent and adult rats. Psychopharmacology 231, 1831-1839.

Sinha, R., 2009. Modeling stress and drug craving in the laboratory: implications for addiction treatment development. Addict. Biol. 14, 84-98.

Staiger, P.K., White, J.M., 1991. Cue reactivity in alcohol abusers: stimulus specificity and extinction of the responses. Addict. Behav. 16, 211-221.

Stapleton, J.M., Morgan, M.J., Phillips, R.L., Wong, D.F., Yung, B.C., Shaya, E.K., Dannals, R.F., Liu, X., Grayson, R.L., London, E.D., 1995. Cerebral glucose utilization in polysubstance abuse. Neuropsychopharmacology 13, 21-31.

Thomas, K.L., Arroyo, M., Everitt, B.J., 2003. Induction of the learning and plasticityassociated gene Zif268 following exposure to a discrete cocaine-associated stimulus. Eur. J. Neurosci. 17, 1964-1972.

Varlinskaya, E.I., Spear, L.P., 2015. Social consequences of ethanol Impact of age, stress, and prior history of ethanol exposure. Physiol. Behav. 148, 145-150.

Volkow, N.D., Fowler, J.S., 2000. Addiction, a disease of compulsion and drive: involvement of the orbitofrontal cortex. Cereb. Cortex 10, 318-325.

Volkow, N.D., Fowler, J.S., Wolf, A.P., Hitzemann, R., Dewey, S., Bendriem, B., Alpert, R. Hoff, A., 1991. Changes in brain glucose metabolism in cocaine dependence and withdrawal. Am. J. Psychiatry 148, 621-626.

Volkow, N.D., Chang, L., Wang, G.J., Fowler, J.S., Ding, Y.S., Sedler, M., Logan, J., Franceschi, D., Gatley, J., Hitzemann, R., Gifford, A., Wong, C., Pappas, N., 2001. Low level of brain dopamine D2 receptors in methamphetamine abusers: association with metabolism in the orbitofrontal cortex. Am. J. Psychiatry 158, 2015-2021.

Walker, B.M., Walker, J.L., Ehlers, C.L., 2008. Dissociable effects of ethanol consumption during the light and dark phase in adolescent and adult Wistar rats. Alcohol 42, 83-89.

Wikler, A., 1973. Dynamics of drug dependence: implications of a conditioning theory for research and treatment. Arch. Gen. Psychiatry 28, 611-616.

Willcocks, A.L., McNally, G.P., 2013. The role of medial prefrontal cortex in extinction and reinstatement of alcohol-seeking in rats. Eur. J. Neurosci. 37, 259-268.

van Haaren, F., Anderson, K., 1994. Sex differences in schedule-induced alcohol consumption. Alcohol 11, 35-40. 